\title{
POTENTIOMETRIC STUDIES ON THE INTERACTION OF ENVIRONMENTALLY HAZARD ZINC (II), CADMIUM (II) AND LEAD (II) IONS WITH NITRILOTRIACETIC ACID AND SOME TETRAZOLES
}

\author{
S.A. Ibrahim*, Y.H. Ebeid ${ }^{* *}$, A.A.A. Boraei ${ }^{* * *}$, I.T. Ahmed $^{* * *}$, and F. \\ M. Ali ${ }^{* * *}$ \\ *Department of Chemistry, Faculty of Science, Assiut University \\ **Department of Chemistry, Faculty of Science, South Valley University (Kena) \\ ***Department of Chemistry, Faculty of Science, Menya University
}

\begin{abstract}
:
The interaction of $\mathrm{Zn}(\mathrm{II})$, $\mathrm{Cd}(\mathrm{II})$ and $\mathrm{Pb}(\mathrm{II})$ ions with nitrilotriacetic acid (NTA) as a primary ligand, 5-aminotetrazole, 1- $\mathrm{H}$ tetrazole and 5-mercapto-1-methyletetrazole, 1,10-phenanthroline and 2,2'-bipyridyl as secondary ligands has been studied in aqueous medium at room temperature. The formation constants for all metal complexes were evaluated using potentiometric titration data. The stability constants were found to depend markedly on the basicity as well as the steric effect of the ligands.
\end{abstract}

\section{INTRODUCTION :}

This work comes as a part of our continuous effor $^{[1-3]}$ on the application of Irving-Rossotti titration technique ${ }^{[4]}$ for studying binary and ternary complexes of variant divalent metal ions with biologically important compounds. Nitrilotriacetic (NTA) is well known as a substituted for phosphates in detergents and tetrazoles have many pharmaceutical applications -as stimulants or sedatives on the central nervous system $^{[5]}$. In addition, tetrazole compounds are useful as oxidizers and effective agents for regulating plant growth and as explosives and rocket propellants ${ }^{[6]}$. Another important feature of these compounds is their ability to form complexes with almost all metal ions. This explains the wide applications and interest on the stability constant and thermodynamic parameters for metal complex formation of the above ligands ${ }^{[7]}$. From another point of view lead is a highly toxic that was used for many years in products found in the environment. So, kind efforts are being devoted to protect human health and the environment 
against the dangers of lead. This enamored us to take an endeavor to determine the stability constants of the binary and ternary complexes of $\mathrm{Pb}(\mathrm{II}), \mathrm{Zn}(\mathrm{II})$ and $\mathrm{Cd}(\mathrm{II})$ with nitrilotriacetic acid and three different tetrazoles. These values are of potential usefulness to environmental and biological problems ${ }^{[8-10]}$.

\section{EXPERIMENTAL:}

\section{MATERIALS AND SOLUTIONS:}

All chemicals used in the present study are either BDH or Sigma products. Stock solutions of metal ions, NTA, tetrazoles, $\mathrm{NaOH}, \mathrm{HNO}_{3}$ and $\mathrm{KNO}_{3}$ for pH-metric titrations were prepared by dissolving an accurately weighed amount of each in doubly distilled water. Solutions of $\mathrm{Zn}^{2+}, \mathrm{Cd}^{2+}$ and $\mathrm{Pb}^{2+}$ were prepared from their nitrates. A $\mathrm{NaOH}$ solution was prepared by dissolving Analar pellets in $\mathrm{CO}_{2}$ free bidistilled water, and the solution was standardized with a standard potassium hydrogen phthalate solution. $\mathrm{HNO}_{3}$ solution was prepared and used after standardization. A total concentration of $2.0 \mathrm{~mol} \mathrm{dm}$ of $\mathrm{KNO}_{3}$ was used as a supporting electrolyte. More dilute solutions were prepared by accurate dilution of the corresponding stock solutions. The structure of the organic compounds used is shown in Fig. (1)

\section{pH-metric Titration:}

The following mixtures were prepared (total volume $50 \mathrm{~mL}$ ) and titrated individually against a standard $\mathrm{NaOH}$ solution.

a-HNO $3\left(7.00-10.00 X 10^{-3} \mathrm{~mol} \mathrm{dm}^{-3}\right)+\mathrm{KNO}_{3}(0.10$ mol dm ${ }^{-3}$ ).

b-Solution a in presence of $2.0 \times 10^{-3} \mathrm{~mol} \mathrm{dm}^{-3}$ of NTA or each tetrazoles.

c-Solution $b$ in presence of $2.0 \times 10^{-3} \mathrm{~mol} \mathrm{dm}^{-3}$ of the metal ion used.
d-Solution c in presence of $2.0 \times 10^{-3} \mathrm{~mol} \mathrm{dm}^{-3}$ of each tetrazole.

pH measurements were carried out at $25^{\circ} \mathrm{C}$ using a Metrohm $702 \mathrm{SM}$ automatic titrator with a combined pH glass electrode equipped with a magnetic stirrer (Swizerland). The accuracy of the instrument was $\pm 0.001 \mathrm{pH}$ unit. The instrument was calibrated using aqueous standard buffers of pH 4.00 (phthalate buffer) and 9.20 (borate buffer). As the ionic strength of the test solution is constant; the hydrogen ion activity can be expressed in terms of concentration. So electrode system was calibrated in aqueous medium in terms of hydrogen ion concentration instead of activities $^{[11]}$.

\section{RESULTS AND DISCUSSION:}

Figure (2) shows a representative set of the experimental titration curves obtained according to the sequence described in the experimental section for different metal ions $\left(\mathrm{Zn}^{2+}, \mathrm{Cd}^{2+}\right.$ and $\left.\mathrm{Pb}^{2+}\right)$ with the ligands. Examination of this figure reveals that the different 1:1 binary metal - NTA complexes are strongly formed at lower $\mathrm{pH}$ values compared to $1: 1$ tetrazoles complexes. This is attained from the divergence of each of the binary complex titration curves from that of the corresponding free ligand solution. Furthermore, both of the binary and ternary complexes begin at lower $\mathrm{pH}$ values than that of free ligands. Moreover, investigation of the titration curves of the binary and ternary systems do not show any buffer zones, indicating that the formed complexes have no tendency to undergo deprotonation. With respect to the titration curves of the different $\mathrm{M}^{2+}$-ligand complexes studied, one may observe that the metal ions $\mathrm{Zn}^{2+}, \mathrm{Cd}^{2+}$ and $\mathrm{Pb}^{2+}$ show high tendency to form binary complexes with bipy or phen where complete complex 
formation takes place at low $\mathrm{pH}$ values. On the other hand, the titration curves of the ternary complexes strongly overlap with those of binary ones at low pH values. This overlap discrete above certain $\mathrm{pH}$ values that are dependent on both the ligand and metal ion and there is a divergence of the ternary system titration curve from that of the corresponding binary $[\mathrm{M}(\mathrm{NTA})]^{\mathrm{n}-2}$ titration curve (curves $f$ and $e$ respectively, in Figure 2). This behavior reveals that the former binary complex afford ternary

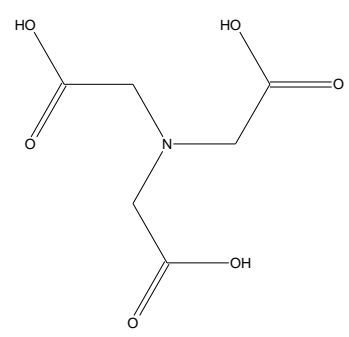

(1)

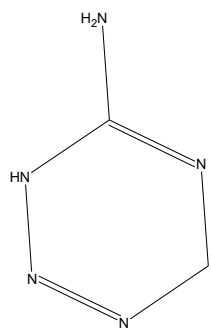

(2)

complexes in a stepwise manner as represented by the following equation:

$$
[\mathrm{M}(\mathrm{NTA})]+\mathrm{HB}^{+}=[\mathrm{M}(\mathrm{NTA}) \mathrm{B}]+\mathrm{H}^{+}(\mathbf{1})
$$

Where $B$ =tetrazoles, bipy or phen, and the formation constants are then given by:

$$
\begin{aligned}
K_{M(N T A)}^{M} & =\frac{[M(N T A)]}{[M]\left[N T A^{3-}\right]} \cdots . . . \\
K_{M(N T A) B}^{M(N T A)} & =\frac{[M(N T A) B]}{[M][N T A]\left[\mathrm{HB}^{+}\right]}
\end{aligned}
$$

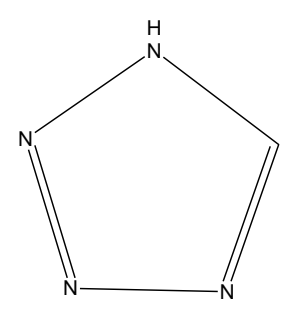

(3)

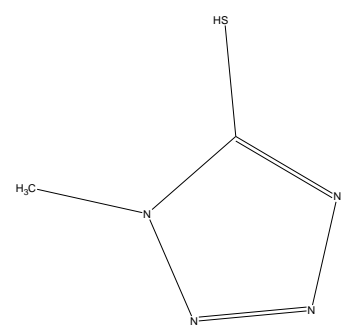

(4)

Fig. (1): The PM3 optimized structures of the investigated compounds:

(1) Nitrilotriacetic acid (NTA).

(3) 1-H tetrazole.

(2) 5-aminotetrazole.

(4) 5-mercapto-1-methyletetrazole.

\section{Formation Constant Values:}

The horizontal distance between curves a and $b$; a and $d$ were used for the calculations of the acidity constant values of tetrazoles and NTA respectively. The formation constans of the binary complexes were determined from the titration curves $b$ and $c ; b$ and $e$; in Figure 2 $\left(\mathrm{HNO}_{3}\right.$ plus tetrazoles or NTA and $\mathrm{HNO}_{3}$ plus tetrazoles or NTA plus $\mathrm{M}^{2+}$, respectively). Moreover, the formation constants of the ternary complexes were calculated from the horizontal distances between curves $e$ and $f$ in Figure (2). The equation used for the calculation of $\bar{n}_{m i x}$ (average number of secondary ligand molecules associated with the [M(NTA)] was the same as that reported in the original paper ${ }^{[4]}$.

$$
\bar{n}_{\text {mix }}=\frac{\left.\left(V_{f}-V_{e}\right)\left[N^{0}+E^{0}+T_{L}^{(y-} n_{H}\right)\right]}{\left(V_{0}+V_{e}\right) n_{H} T_{M}}
$$

Where $T_{M}$ is the concentration of $M^{2+}$ used, $y$ is the number of dissociable protons, and $V_{0}$ is the original volume $\left(50 \mathrm{~cm}^{3}\right), V_{\mathrm{e}}$ and $V_{\mathrm{f}}$ are the volumes of $\mathrm{NaOH}$ consumed to reach the same pH values in curves $e$ and f. All the other symbols have their usual meanings, as reported previously $^{[4]}$. The obtained $\bar{n}_{m i x}$ values were used to calculate the free secondary ligand exponent ( $\left.\mathrm{p} L_{\text {mix }}\right)$ by the following equation:

$$
\mathbf{p} \boldsymbol{L}_{\mathbf{m i x}}=\log \frac{\left[1+10 p K_{a}(1 / 10 A)\right]\left(V_{o}+V_{f}\right)}{\left(T_{l}-\bar{n}_{m i x} T_{M}\right) V_{0}}
$$

Where $K_{\mathrm{a}}$ is the acid dissociation constant of the secondary ligand and $A$ is the pH meter reading. Then the plot of $\bar{n}_{\text {mix }}$ versus $\mathrm{p} L_{\text {mix }}$ gives 
the formation constants of the 1:1:1 ternary complexes by interpolation at half- $\bar{n}_{\text {mix }}$ values (average method). On the other hand, the plot of $\bar{n}_{m i x} / 1-\bar{n}_{m i x}$ versus the concentration of the secondary ligand gave a straight line passing through the origin. The slope of which is equal to $\log K$ for the ternary complexes (straight- line method). The formation constants $(\log K)$ values of the different $1: 1$ binary and 1:1:1 ternary complexes obtained from the corresponding titration curves using the average value and straight line methods ${ }^{[4]}$ are listed in Tables (1 and 2).

From the data cited in Table (1), one can observe that the stability order of the binary system follows the order of basicities of these ligands. This goes hand by hand with the fact that 1,10 -phenanthroline is stronger $\sigma$-donor than bipyridyl. On the other hand, the formation constants of the ternary complexes reported in Table (2) are lower than the corresponding binary ones (Table 1). This can be explained on the principle that coordination

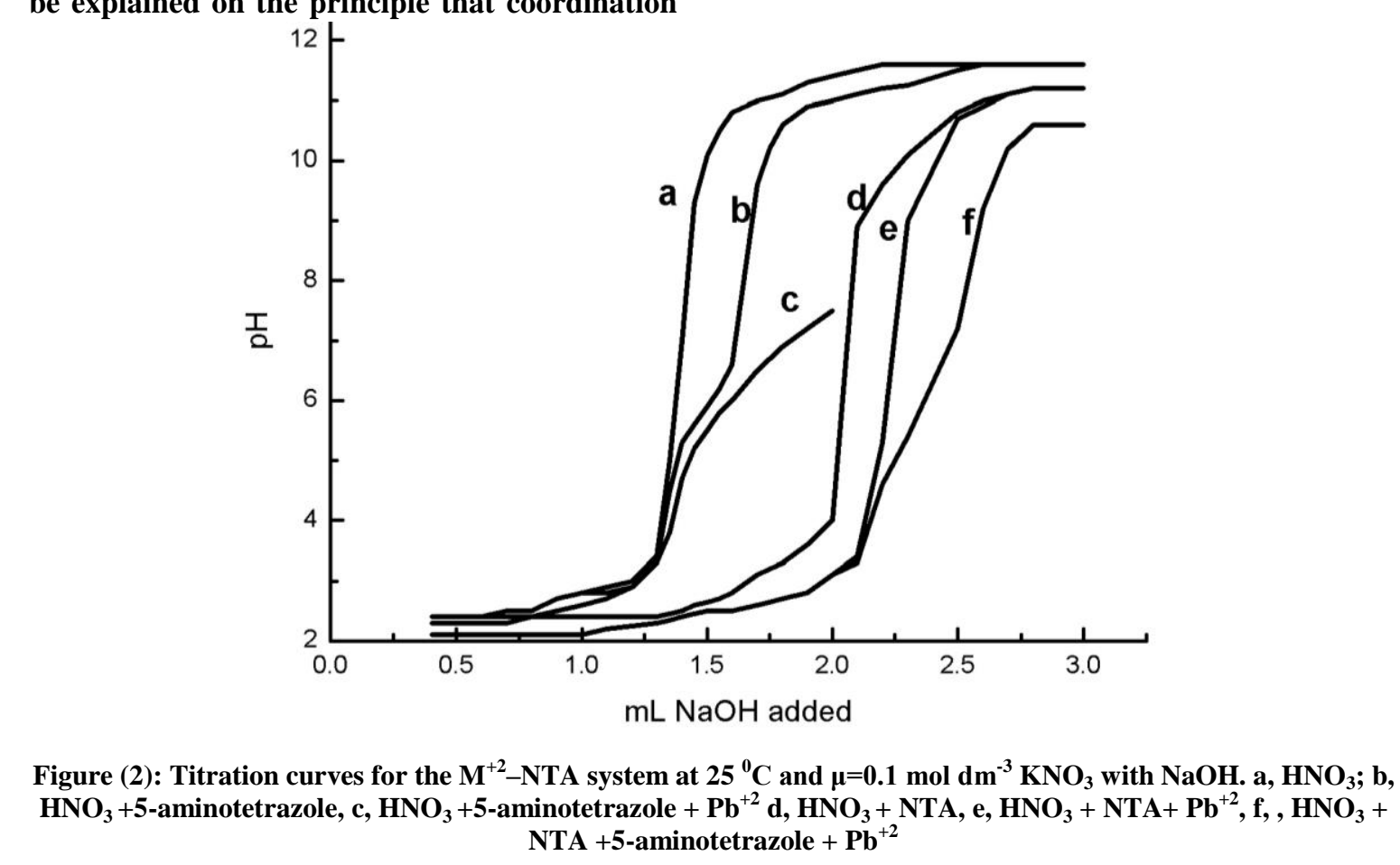

Figure (2): Titration curves for the $\mathrm{M}^{+2}-\mathrm{NTA}$ system at $25{ }^{\circ} \mathrm{C}$ and $\mu=0.1 \mathrm{~mol} \mathrm{dm}^{-3} \mathrm{KNO}_{3}$ with $\mathrm{NaOH}$. a, $\mathrm{HNO}_{3} ; \mathrm{b}$, $\mathrm{HNO}_{3}+5$-aminotetrazole, c, $\mathrm{HNO}_{3}+5$-aminotetrazole $+\mathrm{Pb}^{+2} \mathrm{~d}, \mathrm{HNO}_{3}+\mathrm{NTA}, \mathrm{e}, \mathrm{HNO}_{3}+\mathrm{NTA}+\mathrm{Pb}^{+2}, \mathrm{f}, \mathrm{HNO}_{3}+$ NTA +5-aminotetrazole $+\mathbf{P b}^{+2}$ between the primary ligand NTA and $\mathrm{M}^{+2}$ forms mononegative binary complex and the secondary ligand has to approach the negatively charged primary chelate species [M(NTA)]. Therefore, greater electrostatic repulsion may be expected ${ }^{[12]}$. In the case of binary system, however, ligand anion has to approach the positively charged $\mathrm{M}^{+2}$ and more coordination positions are available for attachment. This reflects the lowering of stability constant values of the mixed ligand complexes. Another important factor that influences the stability of mixed ligand complexes is the steric hindrance of the primary ligand which is already attached with the metal ion ${ }^{[13]}$. Hence $\mathrm{M}^{+2}$ has to expand its coordination number greater than six to form the mixed ligand complex with the secondary ligand and this reflects the greater $\log k_{M L}^{M}$ values higher than $\log k_{M L B}^{M L}$. However, the stability of the ternary complexes are also dependent upon the basicity of the ligand. 
Table (1): Formation constants $\left(\log k_{M L}^{M}\right)$ of the binary $1: 1 \mathrm{M}^{\mathrm{II}}$-Ligand complexes at $25{ }^{0} \mathrm{C}$ and $\boldsymbol{\mu}=0.1 \mathbf{d m}^{-3} \mathrm{KNO}_{3}$

\begin{tabular}{||l|c|c|c|c|c|c|c|c|c||}
\hline \multirow{2}{*}{ Ligand } & \multicolumn{3}{|c|}{ Zn $^{\text {II }}$} & \multicolumn{3}{c|}{ Cd $^{\text {II }}$} & \multicolumn{3}{|c|}{ Pb $^{\text {II }}$} \\
\cline { 2 - 10 } & method1 & Method2 & mean & method1 & method2 & mean & method1 & method2 & mean \\
\hline NTA & 9.97 & 10.09 & 10.03 & 9.68 & 9.80 & 9.74 & 9.88 & 9.81 & 9.84 \\
5-ATZ & 3.42 & 3.33 & 3.38 & 3.72 & 3.69 & 3.71 & 3.30 & 3.21 & 3.26 \\
TZ & 3.17 & 3.31 & 3.24 & 3.97 & 4.08 & 4.02 & 3.00 & 3.00 & 3.00 \\
5-MTZ & 2.94 & 3.07 & 3.05 & 3.06 & 3.05 & 3.06 & 3.20 & 3.22 & 3.21 \\
bipy & 3.15 & 3.15 & 3.15 & 3.55 & 3.51 & 3.53 & 3.47 & 3.52 & 3.50 \\
phen & 3.44 & 3.52 & 3.48 & 3.54 & 3.54 & 3.54 & 4.51 & 4.53 & 4.52 \\
\hline
\end{tabular}

Method 1 and 2 denote to the average and straight-line methods respectively.

Table (2): Formation constants $\left(\log k_{M L B}^{M L}\right)$ of the ternary 1: 1:1 $\mathrm{M}^{\mathrm{II}}$ - ternary Ligand complexes at $25^{\circ} \mathrm{C}$ and $\mu=0.1 \mathrm{dm}^{-3} \mathrm{KNO}_{3}$

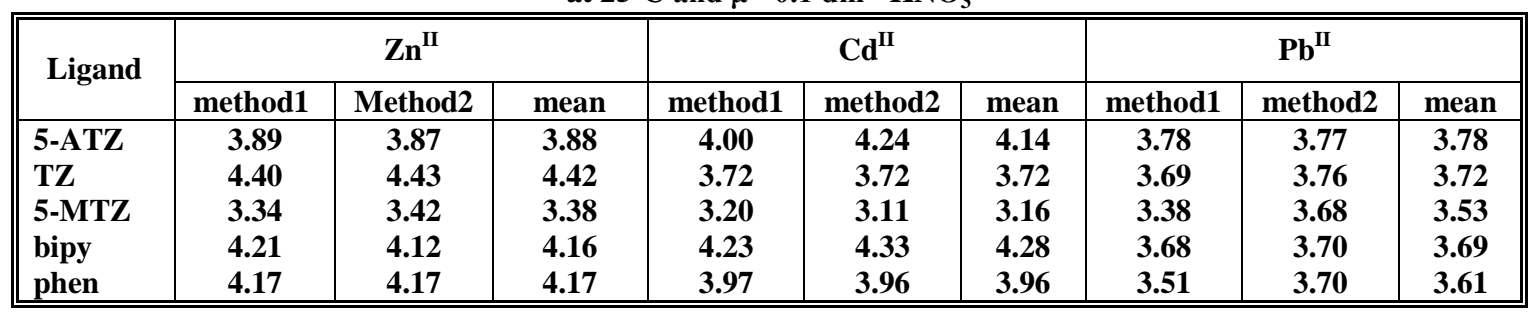

\section{CONCLUSION:}

The interaction of NTA and different tetrazoles with bivalent metal ions of biological interest has been investigated using potentiometric method .The basicity constants of the investigated ligands have a pronounced effect on the formation constants of the binary complexes. On the contrary, the steric effect and the negative charge on the formed binary complexes were the main reasons for the lowering of stability constants of the ternary complexes.

\section{REFERENCES:}

1-A.A.A. Boraei, F. Taha, A.H. Mohamed and S.A. Ibrahim J. Chem. Eng. Data 46, 267 (2001).

2-M. R. Mahmoud, S.A. Ibrahim, A.M. Hassan and I.T. Ahmed, Transition Met. Chem., 21, 1 (1996).

3-O.M. El-Roudi, E.M. Abd Allah and S.A. Ibrahim J. Chem. Eng. Data 42, 609 (1997).

4-H. Irving and H.S. Rossotti, J. Chem. Soc., 3397 (1953); 2904 (1954).
5-T.L. Gllchrist, Heterocyclic Chemistry. $2^{\text {nd }}$ ed.; John Wiley \& Sons: New York, 1992

6-E.O. John, R.L. Kirchmeier and J.M. Shreeve, Inorg. Chem. 28, 4629 (1989).

7-P.G. Daniele, Rigano and S. Sammartano Anal. Chem. 57, 2956 (1985).

8-S. Ramamoorth and P.G.Manning, J.Inorg. Nucl. Chem. 34, P. 1977 (1972).

9-S. Ramamoorth and P.G.Manning, J.Inorg. Nucl. Chem. 34, P. 1989 (1972).

10-P.G. Manning and S. Ramamoorth, J. Inorg. Nucl, Chem. 34, P. 1997 (1972).

11-P.M. May and D.R. Williams, Plenum Press: New York (1985).

12-M. Narasimha Rao, K.L. Omprakash, A.V. Chandra Pal and M.L.N. Reddy, Indian $J$. Chem, 28A,174 (1989).

13-A.M. Pujari and K.N. Munshi, Indian $J$. Chem, 15A, 636 (1977). 
دراسة جهدية على تراكب أيونات الزنك والكادميوم والرصاص الثنائية الضارة للبيئة مع التع نيتريلوثلاثي حمض الخليك وبعض مشثقاث التثرازول في وسط مائى

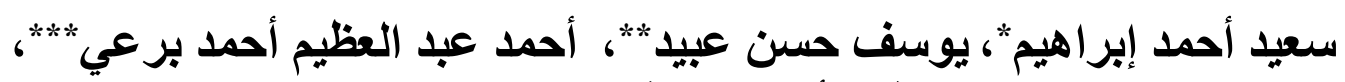

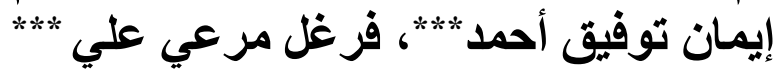

* قسم الكيمياء - كلية العلوم - جامعة أسيوط

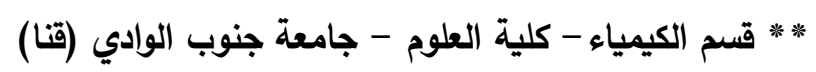

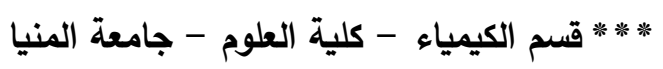

يتضمن البحث دراسة تراكب أيونات عناصر الزنك وإلكادميوم والرصاص الثنائية مع نيتريلوثلاثى حمض ثض

الخليك وبعض مشتقات التترازول في الوسط المائي. وتم حساب ثوابت تكوين المتراكبات عن طريق المعايرات الجهرية، وتبين أن القيم المقدرة تعتمد علي قاعدية المركبات العضوية. 